Gut, 1976, 17, 759-762

\title{
Coeliac disease and dermatitis herpetiformis: further studies of their relationship
}

\author{
B. B. SCOTT, SANDRA YOUNG, S. M. RAJAH, JANET MARKS, AND \\ M. S. LOSOWSKY
}

From the University Department of Medicine, St James's Hospital, Leeds, and the University Department of Dermatology, Royal Victoria Infirmary, Newcastle upon Tyne

SUMMARY Using diagnostic criteria which are currently accepted as most reliable we have found that $19 \%(9 / 47)$ of patients with dermatitis herpetiformis (DH) have no evidence of coeliac disease. The incidence of HL-A8 in the DH patients was $78 \%$, which is considerably greater than that in healthy controls and no different from that reported in coeliac disease. Furthermore, the incidence of HL-A8 was just as much increased in those DH patients without evidence of coeliac disease suggesting that HL-A8 is associated with DH per se-that is, regardless of its association with coeliac disease.

An association between coeliac disease and dermatitis herpetiformis (DH), first suggested by the work of Marks et al. (1966), is now established. However, there is disagreement over the incidence of a mucosal lesion suggestive of coeliac disease in $\mathrm{DH}$-the reports varying from $25 \%$ (Ruppin et al., 1975) to virtually $100 \%$ (Fry et al., 1974). It has been suggested (Fry et al., 1974) that inadequate criteria for the diagnoses are responsible for this wide variation. Certainly, the diagnosis of coeliac disease may not always be straightforward. Some patients may not have the characteristic flat mucosa on a single biopsy, as the lesion may be patchy (Scott and Losowsky, 1975). In some patients the mucosal abnormality may not be severe and be detected only by more sensitive techniques than routine assessment of villous architecture (Robinson et al., 1971; Fry et al., 1972; Stevens et al., 1975). One such technique is interepithelial lymphocyte counting (Ferguson and Murray, 1971; Fry et al., 1972), and, although an increased count may not be specific for coeliac disease, it has been used as an index of mucosal abnormality in DH (Fry et al., 1972; Fry et al., 1974). In the diagnosis of $\mathrm{DH}$ it has been claimed that the usual criteria of clinical and histological features of the rash and response to dapsone may not be completely reliable and that the best criterion is the demonstration of deposits of $\operatorname{IgA}$ at the papillary tips in clinically uninvolved skin (Fry and Seah, 1974). While this is not necessarily true, in order to exclude any patients who might possibly be regarded as

Received for publication 9 June 1976 doubtful we have stipulated the presence of IgA deposits as essential for the diagnosis of DH in this study.

Another link between the two conditions is an increased incidence of the histocompatibility antigen HL-A8. In coeliac disease the reported incidence of HL-A8 is $66-87 \%$, compared with $17-30 \%$ in controls (Falchuk et al., 1972; Albert et al., 1973; Ludwig et al., 1973; McNeish et al., 1973; Stokes et al., 1973; Scott et al., 1974a). In DH the initial reports (Katz et al., 1972; Gebhard et al., 1973; White et al., 1973) showed that incidences of HL-A8 were significantly increased compared with controls (58-68\% compared with $24-31 \%$ ), but less so than in coeliac disease. Two recent reports, however, suggest a similar incidence (Seah et al., 1976; Reunala et al., 1976). Our previous suggestion that the increased incidence of HL-A8 in DH is confined to those with evidence of coeliac disease (Gebhardet al., 1973) may be criticized, as numbers were small and the detection of coeliac disease was not based on multiple biopsies or on interepithelial lymphocyte counting. Furthermore, the criterion of dermal IgA deposits was not used for the diagnosis of DH.

This study was therefore designed to resolve these problems by using the most reliable available criteria for diagnosing $\mathrm{DH}$ and for recognising a mucosal abnormality suggestive of coeliac disease, and determining in a larger series of DH patients: (1) the incidence of coeliac disease, (2) the incidence of HL-A8, and (3) the separate incidences of HL-A8 in DH patients with and without evidence of coeliac disease. 
Methods

PATIENTS

Forty-eight unrelated adult Caucasians with DH from the Leeds and Newcastle regions were studied. They were unselected except by their willingness to take part in the study. Nineteen of the patients had been included in a previous study (Gebhard et al., 1973).

\section{DIAGNOSIS OF DH}

The diagnosis was established in all cases by both the presence of a typical rash and of papillary $\operatorname{IgA}$ in clinically uninvolved skin by direct immunofluorescence. The rash usually consisted of very itchy blisters and/or papules, predominantly on the extensor surfaces, dramatically responsive to treatment with dapsone, and recurring when the drug was stopped. Histologically, the blisters were subepidermal and the papules contained papillary tip abscesses with polymorphs and/or eosinophils. Not all clinical and histological signs were present in every patient but they all had the IgA deposits.

\section{INVESTIGATION FOR EVIDENCE OF COELIAC DISEASE}

Small-intestinal biopsies were taken from all except one patient. In the majority multiple biopsies (two to 15 per patient; mean six) were taken from between the second part of the duodenum and just past the duodenojejunal junction with the hydraulic instrument (Quinton Instruments, Seattle). In the remainder, biopsies were taken from just past the duodenojejunal junction with the Crosby capsule. Biopsies were graded by stereomicroscopy as normal (villous), ridged, convoluted, or flat, and by routine histology as normal, partial villous atrophy, or subtotal villous atrophy. Biopsies from patients in whom no mucosal abnormality was detected were reexamined by interepithelial lymphocyte counting. For this purpose, additional histological sections were stained with PAS and the number of lymphocytes between 500 villous epithelial cells counted. Cinsecutive villous epithelial cells were counted where possible so that all parts of the villi were included. The results were expressed as lymphocytes per 1000 epithelial cells. Two reference ranges were obtained from (1) 33 patients with various other skin conditions who had had small bowel biopsies done in the course of another study and had no symptoms referable to their bowels, 11 had eczema, 13 had psoriasis, and nine had other dermatoses; and (2) 16 patients investigated for abdominal symptoms but with no evidence of organic disease and a final diagnosis of the irritable colon syndrome.

\section{HL-A TYPING}

This was done as previously described (Scott et al., 1974b) in all except seven patients. The incidence of HL-A8 in the local population was estimated by tissue typing 900 healthy subjects consisting of blood donors and hospital and laboratory staff.

\section{Results}

Of the 47 patients submitted to biopsy, $19(40.4 \%)$ had subtotal villous atrophy, $17(36.2 \%)$ had partial villous atrophy, and $11(23.4 \%)$ were normal by both stereomicroscopy and routine histology. Six of these 11 patients had only single biopsies taken. The interepithelial lymphocyte counts for these 11 patients are shown in relation to the two reference ranges in the Figure. Only two had counts above the upper limit of the skin disease reference range (74-428 per 1000 epithelial cells; mean $\pm 2 S D)$, and both these patients had single biopsies. Thus in nine $(19 \%)$ of the DH patients there was no detectable mucosal abnormality, although multiple biopsies had been

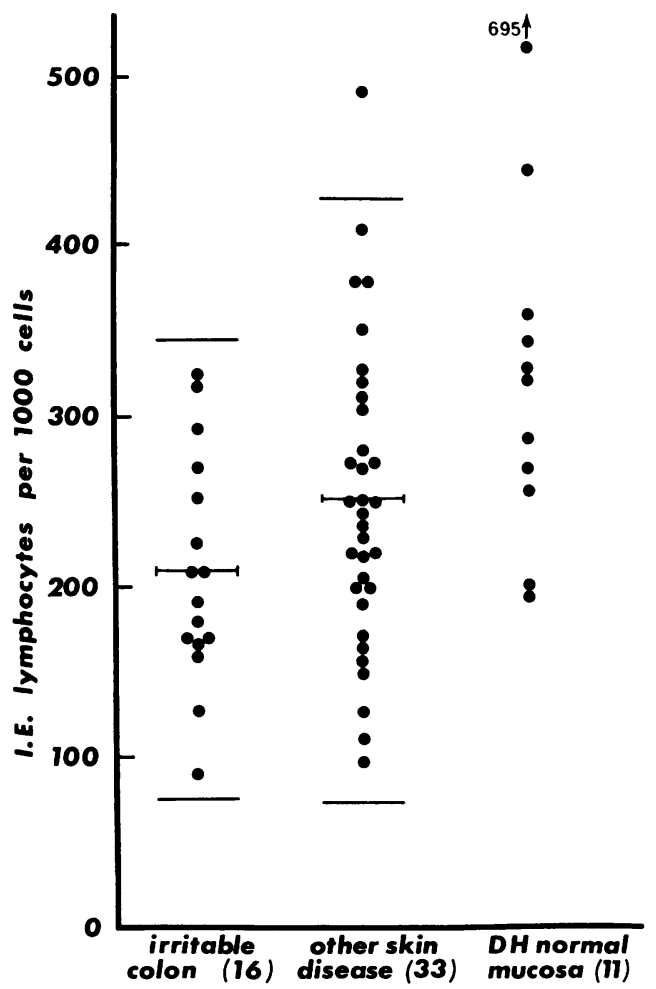

Figure The interepithelial lymphocyte counts obtained from the $11 \mathrm{DH}$ patients with otherwise normal smallintestinal biopsies compared with the two reference ranges. The bars represent the mean $\pm 2 S D$. 
studied in five. The reference range obtained from the patients with the irritable colon syndrome (75345) had a lower upper limit but even using this range only one additional patient had a raised count.

The incidence of HL-A8 in the 900 healthy controls was $29.5 \%$. The overall incidence in the 41 DH patients tested was $\mathbf{7 8} \%$. All the nine patients with completely normal biopsies were typed and eight $(88 \%)$ were HL-A8 positive, this incidence being significantly greater than in healthy controls $(P=0.0004$ using Fisher's exact test). Thirty of the patients with abnormal biopsies were typed and 23 ( $77 \%$ ) were HL-A8 positive. The difference between the incidence of HL-A8 in those with and without evidence of mucosal abnormality was not significant (P > 0.05 using the chi squared test).

\section{Discussion}

Using criteria which are currently suggested as being most reliable for the diagnosis of $\mathrm{DH}$ and most sensitive for detecting a mucosal abnormality suggestive of coeliac disease, we have shown that by no means do all $\mathrm{DH}$ patients have evidence of coeliac disease. These findings are at variance with the conclusion of Fry et al. (1974) who maintain that virtually all $\mathrm{DH}$ patients have coeliac disease. Using stereomicroscopy and routine histology we have detected a rather higher incidence of abnormal mucosae $(77 \%$ compared with $53 \%)$ and this could reflect the use of multiple biopsies or preferential referral of DH patients with suspected gastrointestinal disease. On the other hand, whereas Fry et al. (1974) found nearly all the remaining patients had an increased interepithelial lymphocyte count, we found an increased count in only two out of 11 . However, their reference range was obtained from a smaller number of subjects and was much lower (69285) than our range or the ranges of Ferguson and Murray (1971) (60-400) and Stevens et al. (1975) $(132-450)$. It is therefore possible that fortuitously the control patients chosen by Fry et al. (1974) had abnormally low counts providing an inappropriate reference range. Furthermore, an increased interepithelial lymphocyte count cannot at present be equated with coeliac disease-usually it is necessary to demonstrate an obvious abnormality of villous architecture which improves after treatment with a gluten-free diet.

It may yet be that still more sensitive techniques, perhaps electron microscopy, enzyme studies or stressing with a high gluten diet (Weinstein, 1974) will detect a mucosal abnormality in the $19 \%$ of DH patients with apparently normal biopsies. It is also possible that taking more biopsies would improve detection. However, on the present evidence we must accept that at least one in five DH patients do not have coeliac disease.

The link between the small bowel lesion of coeliac disease and the skin lesion of DH is not understood but it seems possible that the skin lesion is at least partly a result of the deposition of circulating immune complexes derived from the damaged small bowel mucosa in those patients in whom such damage is present. Supporting this is the observation that in some patients the skin as well as the bowel may improve after a gluten-free diet (Marks and Whittle, 1969; Fry et al., 1973), and that circulating immune complexes are commonly found in DH patients and that these tend to disappear on a gluten-free diet (Mowbray et al., 1973). This provides no obvious explanation of the mechanism responsible for the skin lesion in those patients without coeliac disease. It is therefore of interest that we have observed a patient whose rash responded to gluten withdrawal and relapsed after gluten challenge, small-intestinal biopsies being normal throughout.

The incidence of HL-A8 in this large series of DH patients is well within the range of incidences reported in coeliac disease and rather higher than in the three other smaller series of DH patients. Furthermore, we have found that the incidence of HL-A8 is not significantly different in those with and without evidence of coeliac disease. This differs from our previous smaller study (Gebhard et al., 1973) employing less precise criteria. These results suggest that HL-A8 is associated with DH per se-that is, regardless of its association with coeliac disease.

We are grateful for the support of the Scientific and Research Committee of the Royal Victoria Infirmary, Newcastle upon Tyne.

\section{References}

Albert, E. D., Harms, K., Wank, R., Steinbauer-Rosenthal, I., and Scholz, S. (1973). Segregation analysis of HL-A antigens and haplotypes in 50 families of patients with coeliac disease. Transplantation Proceedings, 5, 1785-1789.

Falchuk, Z. M., Rogentine, G. N., and Strober, W. (1972). Predominance of histocompatibility antigen HL-A8 in patients with gluten-sensitive enteropathy. Journal of Clinical Investigation, 51, 1602-1605.

Ferguson, A., and Murray, D. (1971). Quantitation of intraepithelial lymphocytes in human jejunum. Gut, 12, 988-994.

Fry, L., and Seah, P. P. (1974). Dermatitis herpetiformis: an evaluation of diagnostic criteria. British Journal of Dermatology, 90, 137-146.

Fry, L., Seah, P. P., Harper, P. G., Hoffbrand, A. V., and McMinn, R. M. H. (1974). The small intestine in dermatitis herpetiformis. Journal of Clinical Pathology, 27, 817-824.

Fry, L., Seah, P. P., McMinn, R. M. H., and Hoffbrand, A. V. (1972). Lymphocytic infiltration of epithelium in diagnosis of gluten-sensitive enteropathy. British Medical Journal, 3, 371-374. 
Fry, L., Seah, P. P., Riches, D. J., and Hoffbrand, A. V. (1973). Clearance of skin lesions in dermatitis herpetiformis after gluten withdrawal. Lancet, 1, 288-291.

Gebhard, R. L., Katz, S. I., Marks, J., Shuster, S., Trapani, R. J., Rogentine, G. N., and Strober, W. (1973). HL-A antigen type and small-intestinal disease in dermatitis herpetiformis. Lancet, 2, 760-762.

Katz, S. I., Falchuk, Z. M., Dahl, M. V., Rogentine, G. N., and Strober, W. (1972). HL-A8: a genetic link between dermatitis herpetiformis and gluten-sensitive enteropathy. Journal of Clinical Investigation, 51, 2977-2980.

Ludwig, H., Polymenidis, Z., Granditsch, G., and Wick, G. (1973). HL-A1 und HL-A8 bei kinderlicher Coeliäkie. Zeitschuft für Immun itatsforschung, 146, 158-167.

McNeish, A. S., Nelson, R., and Mackintosh, P. (1973). H-LAl and 8 in childhood coeliac disease. (Letter). Lancet, 1, 668.

Marks, J., Shuster, S., and Watson, A. J. (1966). Small-bowel changes in dermatitis herpetiformis. Lancet, 2, 1280-1282.

Marks, R., and Whittle, M. W. (1969). Results of treatment of dermatitis herpetiformis with a gluten-free diet after one year. British Medical Journal, 4, 772-775.

Mowbray, J. F., Hoffbrand, A. V., Holborow, E. J., Seah, P. P., and Fry, L. (1973). Circulating immune complexes in dermatitis herpetiformis. Lancet, 1, 400-402.

Reunala, T., Salo, O. P., Tiilikainen, A., and Mattila, M. J. (1976). Histocompatibility antigens and dermatitis herpetiformis with special reference to jejunal abnormalities and acetylator phenotype. British Journal of Dermatology, 94, 139-143.

Robinson, D. C., Watson, A. J., Wyatt, E. H., Marks, J. M., and Roberts, D. F. (1971). Incidence of small-intestinal mucosal abnormalities and of clinical coeliac disease in the relatives of children with coeliac disease. Gut, 12, 789-793.
Ruppin, H., Weidner, F., Domschke, S., Domschke, W., Classen, M., and Hornstein, O. P. (1975). Dermatitis herpetiformis and small intestinal lesion-no strict association in German patients. Acta Hepato-Gastroenterologica, 22, 105-111.

Scott, B. B., and Losowsky, M. S. (1975). Patchiness of the mucosal abnormality in coeliac disease (CD) and dermatitis herpetiformis (DH). Gut, 16, 393. (Abstract).

Scott, B. B., Losowsky, M. S., and Rajah, S. M. (1974a). HL-A8 and HL-A12 in coeliac disease. (Letter). Lancet, 2, 171.

Scott, B. B., Swinburne, M. L., Rajah, S. M., and Losowsky, M. S. (1974b). HL-A8 and the immune response to gluten. Lancet, 2, 374-377.

Seah, P. P., Fry, L., Kearney, J. W., Campbell, E., Mowbray, J. F., Stewart, J. S., and Hoffbrand, A. V. (1976). A comparison of histocompatibility antigens in dermatitis herpetiformis and adult coeliac disease. British Journal of Dermatology, 94, 131-138.

Stevens, F. M., Lloyd, R., Egan-Mitchell, B., Mylotte, M. J., Fottrell, P. F., Wright, R., McNicholl, B., and McCarthy, C. F. (1975). Reticulin antibodies in patients with coeliac disease and their relatives. Gut, 16, 598-602.

Stokes, P. L., Asquith, P., Holmes, G. K. T., Mackintosh, P., and Cooke, W. T. (1973). Inheritance and influence of histocompatibility (HL-A) antigens in adult coeliac disease. Gut, 14, 627-630.

Weinstein, W. M. (1974). Latent celiac sprue. Gastroenterology, 66, 489-493.

White, A. G., Barnetson, R. St. C., Costa, J. A. G. Da., and McClelland, D. B. L. (1973). The incidence of HL-A antigens in dermatitis herpetiformis. British Journal of Dermatology, 89, 133-136. 